\title{
Outcomes and clinical relevance of stool multiplex bacterial polymerase chain reaction in patients with acute diarrhea: single center experience
}

\author{
Won Gun Kwack ${ }^{1}$, Yun Jeong $\operatorname{Lim}^{1}$, Ki Hwan Kwon ${ }^{1}$, Jae Woo Chung ${ }^{2}$, and Jin Young Oh ${ }^{1}$
}

Departments of ${ }^{1}$ Internal Medicine and ${ }^{2}$ Laboratory Medicine, Dongguk University Ilsan Hospital, Goyang, Korea
Background/Aims: Diagnostic stool multiplex polymerase chain reaction (PCR) testing has attracted considerable interest, because of its high sensitivity, short turnaround time, and ability to detect multiple organisms simultaneously. This study investigates the clinical usefulness of a stool multiplex bacterial PCR in patients with acute diarrhea.

Methods: We retrospectively evaluated the stool multiplex bacterial PCR results, clinical parameters, and clinical courses of patients hospitalized because of acute diarrhea between August 2014 and November 2016.

Results: A total of 725 patients (male, 372; mean age, $30.9 \pm 29.3$ years) underwent stool multiplex bacterial PCR. A total of 243 pathogens were detected in 226 patients. The detection rate of multiplex PCR testing was higher than that of stool culture $(32.7 \%$ vs. $3.3 \%, p<0.01)$. Severe symptoms of acute diarrhea (bloody diarrhea, frequent diarrhea) and prescribed empirical antibiotics were significantly more common in the positive multiplex PCR group $(p=0.02, p<0.01, p<0.01$, respectively). However, mean durations of hospital stay were similar in the 2 groups according to the multiplex PCR results $(p=0.32)$. In addition, Campylobacter spp., which was the most commonly detected pathogen (97/243, 39.9\%), was significantly associated with frequent diarrhea and prescribed empirical antibiotics $(p<0.01)$, but not with duration of hospital stay $(p=0.09)$.

Conclusions: We concluded that stool multiplex bacterial PCR might be a useful tool for identifying bacterial etiology in patients with acute diarrhea, especially in those with Campylobacter spp. infection.

Keywords: Diarrhea; Multiplex polymerase chain reaction; Pathogen; Campylobacter

\section{INTRODUCTION}

Acute diarrhea is common, and in the general population its incidence ranges from 0.6 to 0.8 episodes of illness per person, annually $[1,2]$. Acute diarrhea is usually self-limited (lasting 1 to 3 days) [3], and thus, adequate fluid and electrolyte replacement are often sufficient for its management. Nevertheless, acute diarrhea remains an important cause of morbidity and mortality, particularly in developing countries, and a significant cause of economic loss in industrialized countries [4].

Infection is the most common cause of acute diarrhea. In the past, microbiological examinations were performed, mainly by stool culture or enzyme immu- 
noassay, to identify the causative bacterial agent. Unfortunately, the diagnostic yield of stool culture is very low (ranging from $1.5 \%$ to $5.6 \%$ ) and its minimum turnaround time ranges from 48 to 76 hours [5]. Moreover, enzyme immunoassay is labor intensive and has low sensitivity [6].

In contrast, stool polymerase chain reaction (PCR) testing is more sensitive than standard stool culture [79], has a short (approximately 1 day) turnaround time, and can simultaneously detect multiple organisms.

For these reasons, conventional methods are likely to be replaced by stool multiplex PCR. The recent adoption of the test supports this belief. However, there are still concerns about the usefulness of stool multiplex PCR in a clinical setting. Accordingly, we undertook this study to verify the outcomes and clinical relevance of stool multiplex bacterial PCR testing, by analyzing its results and clinical findings.

\section{METHODS}

This retrospective study was conducted at Dongguk University Ilsan Hospital between August 1, 2014 and November 31, 2016. We initially searched for patients of all ages hospitalized for acute diarrhea and diarrhea-associated symptoms (fever, dehydration, or restlessness) who underwent stool multiplex bacterial PCR testing. We defined acute diarrhea as the passage of $\geq 3$ loose or watery stool within 24 hours, or of $\geq 1$ bloody or mucoid stools [10]. Exclusion criteria were as follows: hospital visits were more than 2 weeks after diarrhea onset, underlying gastrointestinal diseases including inflammatory bowel disease and gastrointestinal cancer, or a lack of clinical information (Fig. 1).

Detailed clinical findings and laboratory parameters were obtained by reviewing electronic medical records. Collected variables were as follows: age, sex, concomitant disease, fever, maximum diarrhea frequency per day, bloody diarrhea and vomiting, blood test (serum leukocyte, C-reactive protein [CRP], blood urea nitrogen, and creatinine), the use of empirical antibiotics, stool test (microscopic examination of white blood cells [WBCs], occult blood, and culture), stool multiplex bacterial PCR, and duration of hospital stay. Fever was defined as a tympanic temperature of $\geq 38.3^{\circ} \mathrm{C}[11,12]$. Severe acute diarrhea was defined as diarrhea with fever, acute kidney injury (prerenal azotemia), bloody diarrhea (grossly or a positive stool occult blood test), or frequent diarrhea (passage of $\geq 6$ unformed stools per 24 hours) [13]. A Charlson comorbidity index score of $\geq 2$ was defined as a "severe underlying disease," including cerebrovascular disease, cardiovascular disease, pulmonary disease, liver cirrhosis, chronic kidney disease, and malignancy [14]. Doctors prescribed empirical antibiotics when they did not expect the diarrhea to be self-limited before stool multiplex PCR results became available.

\section{Stool culture and multiplex PCR}

The hospital conducted a standard stool culture and multiplex PCR at the time of hospital admission. Stool cultures for Salmonella, Shigella, and Vibrio species (spp.) were performed using selective agars: MacConkey (Shinyang Diagnostics, Seoul, Korea), Salmonella-Shigella (Asan Pharm., Seoul, Korea) and xylose lysine deoxycholate agar (Asan Pharm.) after 24 hours of enrichment in selenite broth (Becton, Dickinson and Co., Sparks, CA, USA) for Salmonella spp., and Shigella spp. or thiosulphate citrate bile salt sucrose agar (Asan Pharm.) for Vibrio spp. [15]. Campylobacter spp. was not included in the stool culture. Multiplex PCR was performed using Seeplex Diarrhea-B1/B2 ACE detection kit (Seegene, Seoul, Korea) to simultaneously detect the following microorganisms: Campylobacter spp. (C. jejuni, C. coli), Salmonella spp. (S. enterica, S. bongori), Shigella spp. (S. boydii, S. dysenteriae, S. flexneri, S. Sonnei), Clostridium difficile toxin B, C. perfringens, Vibrio spp. (V. cholerae, V. parahaemolyticus, V. vulnificus), Yersinia enterocolitica, Aeromonas spp. (A. bivalvium, A. hydrophila, A. salmonicida, A. sobria), Escherichia coli $\mathrm{O}_{157}: \mathrm{H}_{7}$, and verotoxin-producing E. coli. Total nucleic acids were extracted from pretreated stool specimens according to the manufacturer's instructions. Simultaneous amplification was performed using the SeeAMP ThermoCycler PCR System (Seegene) [16].

\section{Statistical analysis}

Results are expressed as mean \pm standard deviation $(\mathrm{SD})$ for continuous variables or as numbers and percentages for categorical variables. Chi-square test or Fisher's exact test was used to compare categorical variables while Student's $t$ test was used to compare continuous variables. Detection rates of bacterial pathogens by stan- 
dard stool cultures and multiplex PCR were compared using McNemar's test. Multivariate regression analysis was performed to identify clinical factors independently associated with test results. In the analysis for overall pathogens detected in multiplex PCR, adjusted variables were fever, vomiting, bloody diarrhea, frequent diarrhea, CRP, severe acute diarrhea, use of empirical antibiotics and duration of hospital stay. In the analysis for Campylobacter spp., age, hypertension, diabetes mellitus, severe underlying disease, fever, acute kidney injury, bloody diarrhea, frequent diarrhea, CRP, severe acute diarrhea, use of empirical antibiotics and duration of hospital stay were adjusted. Results are reported as odds ratio (OR) with $95 \%$ confidence interval (CI). Statistical significance was accepted at $p$ values $<0.05$. All statistical analyses were performed using SPSS version 23.0 (IBM Co., Armonk, NY, USA).

The Institutional Review Board of Dongguk University Ilsan Hospital approved this study (approval number: 2015-144). Specimens were obtained as part of the Department of Internal Medicine's routine diagnostic activities. Data were analyzed anonymously. The requirement of informed consent was waived by the Institutional Review Board due to its retrospective nature.

\section{RESULTS}

\section{Demographic and clinical characteristics}

Of the 801 initial patients, 76 patients were excluded; so we included 725 patients in this study (Fig. 1). The mean age of the 725 subjects was $30.9 \pm 29.3$ years. Males made up 372 out of the 725 subjects (51.3\%). One hundred and twenty-four patients (17.1\%) had a severe underlying disease, 230 patients (31.7\%) had fever, 233 (34.6\%) had vomiting, 125 (17.2\%) had bloody diarrhea, 236 (32.6\%) had frequent diarrhea, and 107 patients (14.8\%) had an acute kidney injury.

Stool cultures were tested in 601 patients, out of the 725 who underwent the multiplex PCR test. Of the 601 patients who underwent both stool multiplex PCR and culture, the positive stool culture rate was lower than the positive multiplex PCR rate $(p<0.01)$. The ratio of patients with cultured pathogens was 20/601 (3.3\%), and patients with pathogen detected by multiplex PCR were $173 / 601$ (32.7\%). All the pathogens detected by stool cul-

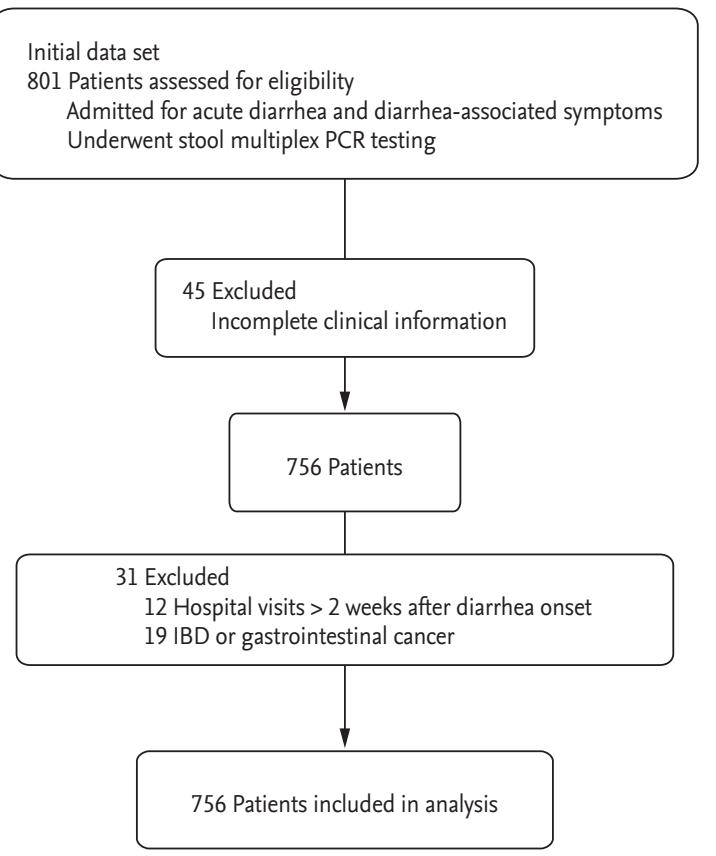

Figure 1. Flow diagram showing patient selection. PCR, polymerase chain reaction; IBD, inflammatory bowel disease.

ture (17 Salmonella spp., three Shigella spp.) exactly concurred with those identified by multiplex PCR. Even when the targeted pathogens of multiplex PCR were limited to the same kinds as found by the stool culture, Salmonella, Shigella, and Vibrio spp., the detection rate of multiplex PCR was higher than that of the stool culture (5.5\% vs. $3.3 \%, p=0.04)$. Overall, doctors prescribed empirical antibiotics for 535 patients (73.8\%); the mean duration of hospital stay was $5.6 \pm 3.4$ days (Table 1 ).

\section{Relationships between clinical findings and stool multiplex PCR results}

Table 2 summarizes the characteristics of patients in the positive and negative PCR groups. A univariate analysis showed bloody diarrhea and frequent diarrhea were more common in the positive PCR group (22.6\% vs. $14.8 \%, p=0.01 ; 43.4 \%$ vs. $27.7 \%, p<0.01$, respectively). Severe acute diarrhea and positive stool WBC results were more common in the positive group $(p<0.01)$, as was the use of empirical antibiotics ( $85.8 \%$ vs. $68.3 \%, p<0.01$ ). However, the mean duration of hospital stays was not significantly different between the two groups $(5.6 \pm 2.9$ days vs. $5.6 \pm 3.6$ days, $p=0.96$ ). A multivariate analysis revealed a significant difference between the two groups 
Table 1. Demographic and clinical characteristics $(n=725)$

\begin{tabular}{lc}
\hline Clinical finding & Value \\
\hline Age, yr & $30.9 \pm 29.3$ \\
Sex, male/female & $372(51.3) / 353(48.7)$ \\
HTN & $132(18.2)$ \\
DM & $97(13.4)$ \\
Severe underlying disease ${ }^{a}$ & $124(17.1)$ \\
Fever & $230(31.7)$ \\
Vomiting & $233(34.6)$ \\
Bloody diarrhea & $125(17.2)$ \\
Frequent diarrhea & $236(32.6)$ \\
Acute kidney injury & $107(14.8)$ \\
Leukocytes, /mm ${ }^{3}$ & $10,828 \pm 6.804$ \\
CRP, mg/L & $5.4 \pm 6.8$ \\
Pathogen detected by multiplex & $226(31.2)$ \\
PCR test & \\
Pathogen detected by stool culture & $20(3.3)$ \\
(n = 6o1) & \\
Positive stool WBC (n = 629) & $53(8.4)$ \\
\hline Use of empirical antibiotics & $535(73.8)$ \\
Duration of hospital stay, day & $5.6 \pm 3.4$ \\
\hline Value are presented as mean \pm SD as & \\
\hline
\end{tabular}

Values are presented as mean $\pm \mathrm{SD}$ or as number (\%). HTN, hypertension; DM, diabetes mellitus; CRP, C-reactive protein; PCR, polymerase chain reaction; WBC, white blood cell.

${ }^{a} \geq 2$ Charlson comorbidity index score. Frequent diarrhea is defined as $\geq 6$ unformed stool passages per 24 hours.

for bloody diarrhea (OR, 1.74; 95\% CI, 1.09 to $2.78 ; p=$ 0.02), frequent diarrhea (OR, 1.93; 95\% CI, 1.29 to $2.91 ; p$ $<0.01$ ), positive stool WBC (OR, 2.01; 95\% CI, 1.11 to 3.65; $p=0.02$ ), and the use of empirical antibiotics (OR, 2.58; $95 \%$ CI, 1.62 to $4.11 ; p<0.01$ ).

\section{The clinical significance of Campylobacter spp., as established by using the stool multiplex PCR test}

The multiplex PCR test detected a total of 243 pathogens in 226 patients. The most commonly-detected pathogen was Campylobacter spp. (39.9\%), followed by C. perfringens (20.2\%), C. difficile toxin B (18.5\%), Salmonella spp. (12.3\%), Aeromonas spp. (4.9\%), and Shigella spp. (2.5\%) (Fig. 2). A subanalysis according to the severity of acute diarrhea showed Campylobacter spp. and Salmonella spp. were more commonly detected in cases of severe acute di- arrhea $(p<0.01, p=0.01$, respectively); other pathogens showed no significant differences (Fig. 3).

For Campylobacter spp., a multivariate analysis, after excluding patients with a positive PCR result for other stool pathogens, showed patients with a severe underlying disease were less prevalent in the positive group ( $p$ $=0.04$ ). Frequent diarrhea was more common and CRP was higher in the positive group $(p<0.01)$. In addition, a positive stool WBC result and the use of empirical antibiotics were more frequent in the positive group $(p=$ $0.02, p<0.01$, respectively). However, the mean duration of hospital stays was similar in the two study groups $(p$ $=0.09)$ (Table 3$)$.

In Salmonella spp., a multivariate analysis showed that the positive PCR group had more incidences of fever and frequent diarrhea than the negative group $(p<0.01$, $p=0.02$, respectively). However, there was no significant difference between the two groups in the positivity of stool WBC, the use of empirical antibiotics, or the mean duration of hospital stays.

\section{DISCUSSION}

Stool multiplex PCR has attracted considerable interest as a diagnostic tool for the early detection of causative pathogens in patients with diarrhea. This diagnostic tool has several advantages over conventional methods, which include increased sensitivity; decreased turnaround time; broad coverage without the need to select specific tests; and reduced sample volume requirements. Several multiplex PCR test kits are now commercially available. The Seeplex Diarrhea-ACE (Seegene) kit, which was used for this study, has received conformite europeenne marking for use in Europe [17]. Previous studies have compared these multiplex PCR tests against conventional detection methods. However, few studies have addressed their clinical relevance.

In this study, the overall prevalence of patients with detected pathogens by multiplex PCR test was 31.2\% (226/725). A search of the literature revealed a wide range of values have been previously reported (30\% to 70\%) [1820], perhaps because of inter-study differences between numbers, types (bacteria, virus, or protozoa) of targeted pathogens and between the characteristics of enrolled patients. This study showed that the positive rate of 
Table 2. The characteristics of patients according to results of stool bacterial multiplex polymerase chain reaction test

\begin{tabular}{|c|c|c|c|c|c|c|}
\hline \multirow{2}{*}{ Clinical finding } & \multirow{2}{*}{$\begin{array}{l}\text { Positive } \\
(\mathrm{n}=226)\end{array}$} & \multirow{2}{*}{$\begin{array}{l}\text { Negative } \\
(\mathrm{n}=499)\end{array}$} & \multicolumn{2}{|c|}{ Univariate analysis } & \multicolumn{2}{|c|}{ Multivariate analysis $^{\mathrm{a}}$} \\
\hline & & & OR $(95 \% \mathrm{CI})$ & $p$ value & OR (95\% CI) & $p$ value \\
\hline Age, yr & $30.8 \pm 27.7$ & $30.9 \pm 30.1$ & $1(0.99-1.01)$ & 0.95 & & \\
\hline Male sex & $124(54.9)$ & $248(49.7)$ & $1.23(0.90-1.69)$ & 0.20 & & \\
\hline HTN & $38(16.8)$ & $94(18.8)$ & $0.87(0.58-1.32)$ & 0.51 & & \\
\hline $\mathrm{DM}$ & $28(12.4)$ & $69(13.8)$ & $0.88\left(0.55^{-1.41}\right)$ & 0.60 & & \\
\hline Severe underlying disease ${ }^{\mathrm{b}}$ & $33(14.6)$ & $91(18.2)$ & $0.77(0.50-1.18)$ & 0.23 & & \\
\hline Fever & $83(36.7)$ & $147(29 \cdot 5)$ & $1.39(0.10-1.94)$ & 0.05 & $1.28(0.83-1.97)$ & 0.26 \\
\hline Acute kidney injury & $30(13 \cdot 3)$ & $77(15 \cdot 4)$ & $0.84(0.53-1.32)$ & 0.45 & & \\
\hline Vomiting & $68(30.1)$ & $183(36.7)$ & $0.74(0.53-1.04)$ & 0.08 & $0.76(0.53-1.09)$ & 0.14 \\
\hline Bloody diarrhea & $51(22.6)$ & $74(14.8)$ & $1.67(1.12-2.49)$ & 0.01 & $1.74(1.09-2.78)$ & 0.02 \\
\hline Frequent diarrhea $^{\mathrm{c}}$ & $98(43.4)$ & $138(27 \cdot 7)$ & $2.00(1.44-2.78)$ & $<0.01$ & $1.93(1.29-2.91)$ & $<0.01$ \\
\hline Leukocytes, $/ \mathrm{mm}^{3}$ & $11,152 \pm 5,448$ & $10,680 \pm 7,336$ & $1.00(1.00-1.00)$ & 0.39 & & \\
\hline $\mathrm{CRP}, \mathrm{mg} / \mathrm{L}$ & $6.3 \pm 6.6$ & $5.0 \pm 6.9$ & $1.03(1.00-1.05)$ & 0.02 & $1.01(0.98-1.03)$ & 0.54 \\
\hline Positive stool WBC $(\mathrm{n}=629)$ & $29 / 198(14.6)$ & $24 / 431(5 \cdot 6)$ & $2.91(1.65-5.15)$ & $<0.01$ & $2.01(1.11-3.65)$ & 0.02 \\
\hline Severe acute diarrhea $^{\mathrm{d}}$ & $177(78.3)$ & $325(65.1)$ & $1.93(1.34-2.79)$ & $<0.01$ & $0.87(0.50-1.49)$ & 0.61 \\
\hline Use of empirical antibiotics & $194(85.8)$ & $341(68.3)$ & $2.81(1.85-4.27)$ & $<0.01$ & $2.58(1.62-4.11)$ & $<0.01$ \\
\hline Duration of hospital stay, day & $5.6 \pm 2.9$ & $5.6 \pm 3.6$ & $1.00\left(0.95^{-1.05)}\right.$ & 0.96 & $0.97(0.92-1.03)$ & 0.32 \\
\hline
\end{tabular}

Values are presented as mean \pm SD or number (\%).

OR, odds ratio; CI, confidence interval; HTN, hypertension; DM, diabetes mellitus; CRP, C-reactive protein; WBC, white blood cell. ${ }^{a}$ Adjusted for fever, vomiting, bloody diarrhea, frequent diarrhea, CRP, severe acute diarrhea, use of empirical antibiotics and duration of hospital stay.

$\mathrm{b}_{\geq 2}$ Charlson comorbidity index score.

${ }^{c} \geq 6$ unformed stool passages per 24 hours.

${ }^{\mathrm{d}}$ Diarrhea with fever, acute kidney injury, bloody diarrhea or frequent diarrhea.

multiplex PCR testing was higher than that of stool culture (32.7\% vs. $3.3 \%, p<0.01$ ). Evidently, smaller numbers of targeted pathogens (three species) result in lower diagnostic yields for stool culture, although this result reflects clinical practice, where miscellaneous pathogens cannot be cultured because of cost or workload.

In previous studies, bloody diarrhea and frequent diarrhea were more commonly presented by patients with acute bacterial diarrhea [21,22]. In this study, although severe acute diarrhea, defined as diarrhea with one of severe symptoms, showed no significance in the multivariate analysis, bloody diarrhea and frequent diarrhea were more common among patients with a positive multiplex PCR test $(p=0.02, p<0.01$, respectively). These findings suggest that a significant correlation exists between stool bacterial multiplex PCR test results and the severe symptoms of acute diarrhea. Vomiting tended to be more frequent in the negative group $(p=0.08)$, per- haps because vomiting is common in diarrheal diseases of viral origin $[23,24]$ and the multiplex PCR test used in this study did not include viral genera. The presence of WBCs in stool suggests an inflammatory process caused by bacterial spp., such as Salmonella spp., Shigella spp., C. jejuni, or C. difficile. In this study, the WBCs detection rate was higher in the positive multiplex PCR group ( $p$ $=0.02$ ).

The empirical antibiotics were prescribed by attending doctors according to patients' overall condition such as the frequency of diarrhea, bloody diarrhea, and fever and, as above mentioned, these severe symptoms were relatively more common in acute bacterial diarrhea, which would explain why that the taking of antibiotics showed positive correlation with the positive result of stool multiplex bacterial PCR. The administration of empirical antibiotics was decided on without the confirmation of multiplex PCR results, and we were not able to 


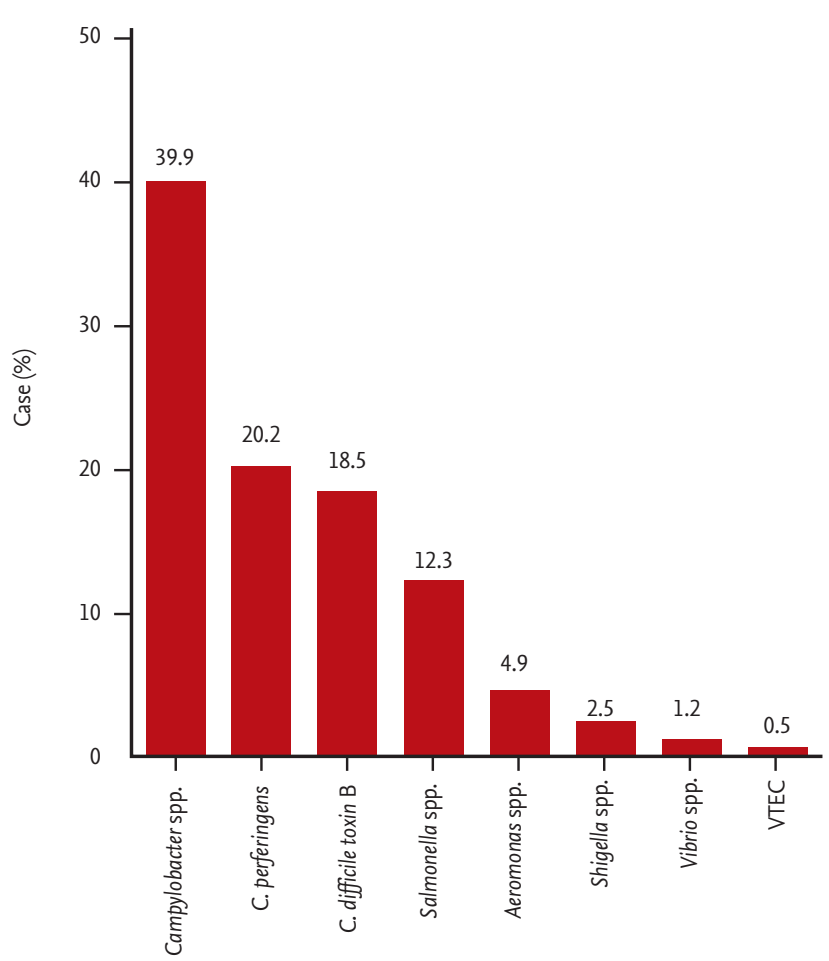

Figure 2. Detected pathogens by stool bacterial multiplex polymerase chain reaction test in acute diarrhea $(n=243)$. $C$. perfringens, Clostridium perfringens; C. difficile, Clostridium difficile; VTEC, verotoxin-producing Escherichia coli.

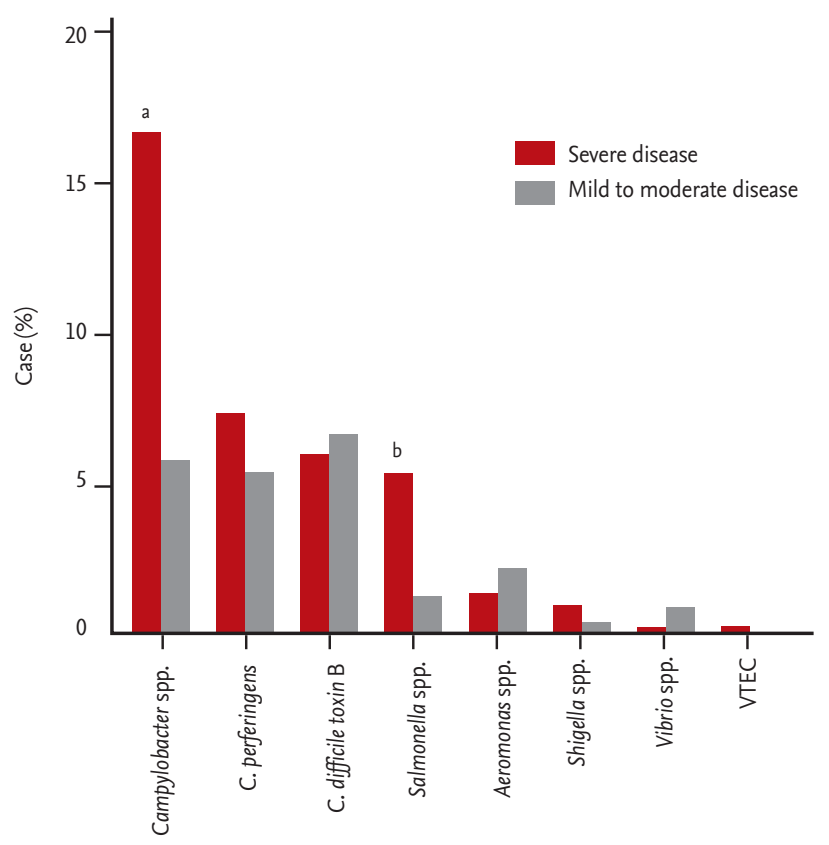

Figure 3. The comparison of detection rates of pathogens by stool bacterial multiplex polymerase chain reaction test according to the severity of acute diarrhea. C. perfringens, Clostridium perfringens; C. difficile, Clostridium difficile; VTEC, verotoxin-producing Escherichia coli. ${ }^{\mathrm{a}} \mathrm{p}<0.01,{ }^{\mathrm{b}} \mathrm{p}=0.01$. discover whether a negative multiplex PCR result might lead to taking patients off antibiotics. Furthermore, the duration of hospital stays as a prognostic factor showed no difference between the two groups according to the multiplex PCR results. Therefore, so far, it is hard to say whether multiplex PCR has certain usefulness in clinical practice for acute diarrhea. Nevertheless, the multiplex PCR showed a high detection rate and had a positive correlation with symptoms associated with bacterial etiology and with the use of empirical antibiotics. These results indicate that multiplex PCR has advantages for identifying the culprit bacterial pathogen and for providing additional information on the appropriateness of antibiotics. These advantages could allow bacterial multiplex PCR to take over much of the role of stool WBC and culture testing for acute diarrhea. Consequently, increasing the use of bacterial multiplex PCR could reduce the use of stool WBC and culture testing. However, concerns about the significance of certain pathogens targeted by multiplex PCR and about the cost-effectiveness of the technique still remain, because stool multiplex PCR is much more expensive than stool WBC testing and stool culture [25].

Campylobacter infection is recognized as a major cause of gastroenteritis [26-28]. Previous epidemiologic studies using stool cultures have reported that the most common pathogen for acute diarrhea was Salmonella, followed by Campylobacter. However, in this study, Campylobacter spp. was the most common bacterial pathogen detected by stool multiplex PCR in acute diarrhea patients (39.9\%), perhaps because stool PCR testing increased the Campylobacter spp. detection rate. Buchan et al. [29] reported that PCR testing had a higher sensitivity (100\%) than culture (76.9\%) for Campylobacter spp. (C. jejuni and C. coli). Although the possibility of a false-positive should also be considered, the multiplex PCR test could show the real etiological importance of Campylobacter spp. in acute diarrhea, as validated by previous studies. In addition, these previous studies reported that the true positive rate of a PCR test for Campylobacter spp. was high $(83.3 \%)$ by repeating different PCR tests; they found a similar proportion of Campylobacter spp. on detected pathogens by stool multiplex PCR (39.5\%) [30,31].

In this study, we found Campylobacter spp. to be significantly associated with frequent diarrhea and high CRP $(p<0.01)$. Furthermore, the use of empirical antibiotics 
Table 3. The characteristics of patients according to the result for Campylobacter spp. in stool bacterial multiplex polymerase chain reaction test

\begin{tabular}{|c|c|c|c|c|c|c|}
\hline \multirow{2}{*}{ Clinical finding } & \multirow{2}{*}{$\begin{array}{r}\text { Positive } \\
(\mathrm{n}=97)\end{array}$} & \multirow{2}{*}{$\begin{array}{l}\text { Negative }^{\mathrm{a}} \\
(\mathrm{n}=499)\end{array}$} & \multicolumn{2}{|c|}{ Univariate analysis } & \multicolumn{2}{|c|}{ Multivariate analysis ${ }^{\mathrm{b}}$} \\
\hline & & & OR $(95 \%$ CI $)$ & $p$ value & OR $(95 \% \mathrm{CI})$ & $p$ value \\
\hline Age, yr & $26.4 \pm 20.7$ & $30.9 \pm 30.1$ & $1(0.99-1.01)$ & 0.15 & $1.01(1.00-1.03)$ & 0.07 \\
\hline Male sex & $55(56.7)$ & $248(49 \cdot 7)$ & $1.33(0.90-2.05)$ & 0.21 & & \\
\hline HTN & $5(5.2)$ & $94(18.8)$ & $0.23(0.09-0.59)$ & $<0.01$ & $0.32(0.11-0.97)$ & 0.04 \\
\hline $\mathrm{DM}$ & $4(4 \cdot 1)$ & $69(13.8)$ & $0.27(0.10-0.75)$ & 0.01 & $0.43(0.13-1.43)$ & 0.17 \\
\hline Severe underlying disease ${ }^{c}$ & $4(4 \cdot 1)$ & $91(18.2)$ & $0.19(0.07-0.54)$ & $<0.01$ & $0.31(0.10-0.96)$ & 0.04 \\
\hline Fever & $44(45 \cdot 4)$ & $147(29.5)$ & $1.99(1.28-3.10)$ & $<0.01$ & $1.18(0.63-2.20)$ & 0.60 \\
\hline Acute kidney injury & $8(8.2)$ & $77(15 \cdot 4)$ & $0.49(0.23-1.06)$ & 0.07 & $0.56(0.22-1.43)$ & 0.23 \\
\hline Vomiting & $31(32.0)$ & $183(36.7)$ & $0.81\left(0.5^{1-1.29)}\right.$ & 0.38 & & \\
\hline Bloody diarrhea & $21(21.6)$ & $74(14.8)$ & $1.59(0.92-2.73)$ & 0.10 & $1.50(0.77-2.92)$ & 0.23 \\
\hline Frequent diarrhea $^{\mathrm{d}}$ & $51(52.6)$ & $138(27.7)$ & $2.90(1.86-4.52)$ & $<0.01$ & $2.17(1.22-3.87)$ & $<0.01$ \\
\hline Leukocytes, $/ \mathrm{mm}^{3}$ & $10,522 \pm 3,801$ & $10,680 \pm 7,336$ & $1.00(1.00-1.00)$ & 0.84 & & \\
\hline $\mathrm{CRP}, \mathrm{mg} / \mathrm{L}$ & $8.6 \pm 6.1$ & $5.0 \pm 6.9$ & $1.06(1.03-1.09)$ & $<0.01$ & $1.06(1.02-1.09)$ & $<0.01$ \\
\hline Positive stool WBC $(\mathrm{n}=517)$ & $24 / 86(27 \cdot 9)$ & $24 / 431(5 \cdot 6)$ & $6.57(3.51-12.27)$ & $<0.01$ & $5.99(2.81-12.77)$ & 0.02 \\
\hline Severe acute diarrhea ${ }^{\mathrm{e}}$ & $84(86.6)$ & $325(65.1)$ & $3.46(1.88-6.38)$ & $<0.01$ & $1.33(0.54-3.28)$ & 0.54 \\
\hline Use of empirical antibiotics & $92(94.8)$ & $341(68.3)$ & $8.53(3.40-21.38)$ & $<0.01$ & $6.35(2.38-16.91)$ & $<0.01$ \\
\hline Duration of hospital stay, day & $5.1 \pm 2.2$ & $5.6 \pm 3.6$ & $1.00(0.89-1.02)$ & 0.17 & $0.92(0.83-1.01)$ & 0.09 \\
\hline
\end{tabular}

Values are presented as mean $\pm \mathrm{SD}$ or number (\%).

OR, odds ratio; CI, confidence interval; HTN, hypertension; DM, diabetes mellitus; CRP, C-reactive protein; WBC, white blood cell. ${ }^{a}$ Excluded patients that tested positive for other stool pathogens by multiplex polymerase chain reaction.

bAdjusted for Age, HTN, DM, severe underlying disease, fever, acute kidney injury, bloody diarrhea, frequent diarrhea, CRP, sever acute diarrhea, use of empirical antibiotics and duration of hospital stay.

$c_{\geq 2}$ Charlson comorbidity index score.

$\mathrm{d}_{\geq} 6$ unformed stool passage per 24 hours.

${ }^{\mathrm{e}}$ Diarrhea with fever, acute kidney injury, bloody diarrhea or frequent diarrhea.

was more common in Campylobacter-positive patients ( $p$ $<0.01$ ). On the other hand, hospital stays were no different in the multiplex PCR positive and negative groups $(p$ $=0.09)$. As mentioned above, in discussing the utility of stool multiplex PCR testing, these results suggest that the multiplex PCR test can increase the detection rate of Campylobacter spp. as a pathogen for acute diarrhea and provide additional information on the appropriate antibiotics, despite the observation that Campylobacter positivity was not associated with prognosis.

Campylobacter selective agar preparation and the time needed for microaerobic incubation $\left(2\right.$ days at $37^{\circ} \mathrm{C}$ ) produce a considerable workload. For these reasons, routine stool cultures in our institution have not included Campylobacter spp. The stool multiplex PCR test for Campylobacter spp. could reduce the labor required to culture.
Furthermore, early identification of Campylobacter as a causative pathogen offers advantages in terms of antibiotic selection. In particular, delayed stool culture turnaround times often result in the indiscriminate use of broad-spectrum antibiotics, such as fluoroquinolones. Its indiscriminate use has resulted in a high resistance rate of Campylobacter spp. against fluoroquinolones. The short turnaround time of stool multiplex PCR testing would provide more opportunity to use macrolide in cases of Campylobacter-associated diarrhea [32] and decrease the risk of hemolytic uremic syndrome associated with broad-spectrum antibiotics in cases of Shiga toxin-producing, E. coli-associated diarrhea [33]. Obviously, investigation on the prevalence of macrolide-resistant Campylobacter spp. should also be carried out.

Campylobacter infection can cause severe, prolonged 
or relapsing illness and bacteremia in immune-compromised patients. In a study in the United States, the incidence of Campylobacter infection was found to be 40 times higher in people with acquired immunodeficiency syndrome than in the general population [34]. However, in this study, somewhat unexpectedly, patients positive for Campylobacter spp. had a lower prevalence of severe underlying disease. This may have been due to lower consumptions of raw poultry and milk, the main sources of Campylobacter in the food chain [35], and less frequent travel by patients with severe underlying disease [36].

In this study, the detection rate of multiplex PCR test for C. perfringens, a common cause of food poisoning, was relatively higher than that by stool culture in former studies. In a study about the limit of detection according to a bacterial load of stool, the stool PCR test had a higher or equal sensitivity for $C$. perfringens and Campylobacter spp. than did stool culture [37,38]. Thus, a stool multiplex PCR test would be helpful in detecting $C$. perfringens as a pathogen in acute diarrhea. Although not all of them can be defined as a community-acquired C. difficile infection, this study suggests an increased prevalence of community-acquired $C$. difficlie infection and virulence because of an increased use of antibiotics. Further study using the PCR test is therefore warranted for community-acquired C. difficlie infection, especially in pediatric patients, because $44.4 \%$ (20/45) of positive C. difficile toxin findings were younger than 15 years old.

This study has several limitations. First, other than Campylobacter spp., few pathogens were detected by multiplex PCR. A larger sample is needed to establish the clinical relevance of testing for other pathogens. Second, unfortunately, the exact collection time of stool multiplex bacterial PCR tests could not be identified because of the limitations of retrospective study. Stool specimens might be collected after use of empirical antibiotics in real clinical situation. In addition, the quality of stool samples could not be controlled either. These factors might explain the relatively low pathogen detection rate of multiplex PCR. Third, multiplex PCR using ipaH and vif as target genes cannot differentiate Shigella spp. from enteroinvasive E. coli. Duplex, real-time PCR using the lacY gene, a gene encoding lactose permease, and the $\beta$-glucuronidase gene could be used for the discrimination in further study [39]. Fourth, it remains unclear whether the pathogens detected by stool multiplex PCR were actually the cause of acute diarrhea. Despite this limitation, we focused on evaluating the clinical usefulness of stool multiplex PCR in a real clinical setting, and we believe our findings shed light on the relevance and clinical utility of broadly based multiplexed PCR testing for the detection of potentially colonizing pathogens/ pseudo pathogens. To establish more accurately the meaning of a positive PCR test result, we suggest that a study be undertaken to compare the clinical characteristics of PCR-positive/culture-positive and PCR-positive/ culture-negative acute diarrhea patients.

In conclusion, although it is uncertain whether a stool bacterial multiplex PCR test influences disease prognosis, the test results correlated with severe symptoms and the use of empirical antibiotics. Thus, the stool bacterial multiplex PCR test might be a useful tool for identifying pathogens and providing additional information on appropriate antibiotics in acute diarrhea cases, especially in those with a Campylobacter infection.

\section{KEY MESSAGE}

1. Positive result in stool multiplex polymerase chain reaction (PCR) test correlates with severe symptoms and the use of empirical antibiotics in acute diarrhea, especially with Campylobacter infection.

2. The stool multiplex PCR test could provide more information about the bacterial etiology of acute diarrhea, because of its relatively high detection rate. If the cost-effectiveness improves, this technique will be an important part of the stool test.

\section{Conflict of interest}

No potential conflict of interest relevant to this article was reported.

\section{REFERENCES}

1. Dingle JH, Badger GF, Jordan WS Jr. Illness in the Home: A Study of 25,000 Illnesses in a Group of Cleveland Fam- 
ilies. Cleveland $(\mathrm{OH})$ : Western Reserve University Press, 1964.

2. Monto AS, Koopman JS. The Tecumseh study. XI. Occurrence of acute enteric illness in the community. Am J Epidemiol 1980;112:323-333.

3. Herikstad H, Yang S, Van Gilder TJ, et al. A population-based estimate of the burden of diarrhoeal illness in the United States: FoodNet, 1996-7. Epidemiol Infect 2002;129:9-17.

4. Guerrant RL, Hughes JM, Lima NL, Crane J. Diarrhea in developed and developing countries: magnitude, special settings, and etiologies. Rev Infect Dis 1990;12 Suppl 1:S41-S50.

5. Guerrant RL, Van Gilder T, Steiner TS, et al. Practice guidelines for the management of infectious diarrhea. Clin Infect Dis 2001;32:331-351.

6. Luna RA, Boyanton BL Jr, Mehta S, et al. Rapid stoolbased diagnosis of Clostridium difficile infection by real-time PCR in a children's hospital. J Clin Microbiol 2011;49:851-857.

7. de Boer RF, Ott A, Guren P, van Zanten E, van Belkum A, Kooistra-Smid AM. Detection of Campylobacter species and Arcobacter butzleri in stool samples by use of real-time multiplex PCR. J Clin Microbiol 2013;51:253-259.

8. de Boer RF, Ott A, Kesztyus B, Kooistra-Smid AM. Improved detection of five major gastrointestinal pathogens by use of a molecular screening approach. J Clin Microbiol 2010;48:4140-4146.

9. Pancholi P, Kelly C, Raczkowski M, Balada-Llasat JM. Detection of toxigenic Clostridium difficile: comparison of the cell culture neutralization, Xpert C. difficile, Xpert C. difficile/Epi, and Illumigene C. difficile assays. J Clin Microbiol 2012;50:1331-1335.

10. Manatsathit S, Dupont HL, Farthing M, et al. Guideline for the management of acute diarrhea in adults. J Gastroenterol Hepatol 2002;17 Suppl:S54-S71.

11. O'Grady NP, Barie PS, Bartlett JG, et al. Guidelines for evaluation of new fever in critically ill adult patients: 2008 update from the American College of Critical Care Medicine and the Infectious Diseases Society of America. Crit Care Med 2008;36:1330-1349.

12. Laupland KB. Fever in the critically ill medical patient. Crit Care Med 2009;37(7 Suppl):S273-S278.

13. DuPont HL. Guidelines on acute infectious diarrhea in adults. The Practice Parameters Committee of the American College of Gastroenterology. Am J Gastroenterol
1997;92:1962-1975

14. Charlson ME, Pompei P, Ales KL, MacKenzie CR. A new method of classifying prognostic comorbidity in longitudinal studies: development and validation. J Chronic Dis 1987;40:373-383.

15. Health Protection Agency. Investigation of faecal specimens for bacterial pathogens [Internet]. London (UK): Health Protection Agency, c2007 [cited 2019 Jan 9]. Available from: http://www.hpa-standardmethods.org.uk/pdf bacteriology.asp.

16. Coupland LJ, McElarney I, Meader E, et al. Simultaneous detection of viral and bacterial enteric pathogens using the Seeplex ${ }^{\circledR}$ Diarrhea ACE detection system. Epidemiol Infect 2013;141:2111-2121.

17. Humphries RM, Linscott AJ. Laboratory diagnosis of bacterial gastroenteritis. Clin Microbiol Rev 2015;28:3-31.

18. Higgins RR, Beniprashad M, Cardona M, Masney S, Low DE, Gubbay JB. Evaluation and verification of the Seeplex Diarrhea-V ACE assay for simultaneous detection of adenovirus, rotavirus, and norovirus genogroups I and II in clinical stool specimens. J Clin Microbiol 2011;49:31543162 .

19. Bruijnesteijn van Coppenraet LE, Dullaert-de Boer M, Ruijs GJ, et al. Case-control comparison of bacterial and protozoan microorganisms associated with gastroenteritis: application of molecular detection. Clin Microbiol Infect 2015;21:592.e9-592.e19.

20. Yoo JW, Lee JR, Jung YK, et al. A combination of early warning score and lactate to predict intensive care unit transfer of inpatients with severe sepsis/septic shock. Korean J Intern Med 2015;30:471-477.

21. Thielman NM, Guerrant RL. Clinical practice. Acute infectious diarrhea. N Engl J Med 2004;350:38-47.

22. DuPont HL. Clinical practice. Bacterial diarrhea. N Engl J Med 2009;361:1560-1569.

23. Park SI, Giannella RA. Approach to the adult patient with acute diarrhea. Gastroenterol Clin North Am 1993;22:483497.

24. Stroni GP, Dhimolea MM, Pipero PS, Kraja DV, Sallavaci SY, Bino SF. A study on the epidemiology and aetiology of acute gastroenteritis in adult patients presenting at the infectious diseases hospital in tirana, Albania. Balkan Med J 2014;31:196-201.

25. Health Insurance Review and Assessment Service. Health insurance reimbursement Health Insurance Review and Assessment Service [Internet]. Wonju (KR): Health Insur- 
ance Review and Assessment Service, c2017 [cited 2019 Jan 9]. Available from: http://www.hira.or.kr/sViewer/index. do?ebookSn=474.

26. Blaser MJ. Epidemiologic and clinical features of Campylobacter jejuni infections. J Infect Dis 1997;176 Suppl 2:S103-S105.

27. Tauxe RV. Emerging foodborne diseases: an evolving public health challenge. Emerg Infect Dis 1997;3:425-434.

28. Mead PS, Slutsker L, Dietz V, et al. Food-related illness and death in the United States. Emerg Infect Dis 1999;5:607-625.

29. Buchan BW, Olson WJ, Pezewski M, et al. Clinical evaluation of a real-time PCR assay for identification of Salmonella, Shigella, Campylobacter (Campylobacter jejuni and C. coli), and shiga toxin-producing Escherichia coli isolates in stool specimens. J Clin Microbiol 2013;51:40014007 .

30. O'Leary J, Corcoran D, Lucey B. Comparison of the EntericBio multiplex PCR system with routine culture for detection of bacterial enteric pathogens. J Clin Microbiol 2009;47:3449-3453.

31. Cho MC, Noh SA, Kim MN, Kim KM. Direct application of multiplex PCR on stool specimens for detection of enteropathogenic bacteria. Korean J Clin Microbiol 2010;13:162-168.

32. Allos BM. Campylobacter jejuni Infections: update on emerging issues and trends. Clin Infect Dis 2001;32:12011206.
33. Wong CS, Jelacic S, Habeeb RL, Watkins SL, Tarr PI. The risk of the hemolytic-uremic syndrome after antibiotic treatment of Escherichia coli O157:H7 infections. N Engl J Med 2000;342:1930-1936.

34. Sorvillo FJ, Lieb LE, Waterman SH. Incidence of campylobacteriosis among patients with AIDS in Los Angeles County. J Acquir Immune Defic Syndr 1991;4:598-602.

35. Saeed AM, Harris NV, DiGiacomo RF. The role of exposure to animals in the etiology of Campylobacter jejuni/ coli enteritis. Am J Epidemiol 1993;137:108-114.

36. Feodoroff B, Lauhio A, Ellstrom P, Rautelin H. A nationwide study of Campylobacter jejuni and Campylobacter coli bacteremia in Finland over a 10-year period, 1998-2007, with special reference to clinical characteristics and antimicrobial susceptibility. Clin Infect Dis 2011;53:e99-e106.

37. Wise MG, Siragusa GR. Quantitative detection of Clostridium perfringens in the broiler fowl gastrointestinal tract by real-time PCR. Appl Environ Microbiol 2005;71:3911-3916.

38. Ganji L, Azimirad M, Farzi N, et al. Comparison of the detection limits of the culture and PCR methods for the detection of Clostridium difficile, Clostridium perfringens, Campylobacter jejuni, and Yersinia enterocolitica in human stool. Arch Pediatr Infect Dis 2016;5:e38888.

39. Pavlovic M, Luze A, Konrad R, et al. Development of a duplex real-time PCR for differentiation between E. coli and Shigella spp. J Appl Microbiol 2011;110:1245-1251. 